Utah State University

DigitalCommons@USU

$1-1-2003$

\title{
Component Level Prediction Versus System Level Measurement of SABER Relative Spectral Response
}

\author{
S. Hansen \\ J. Peterson \\ R. Esplin \\ J. Tansock
}

Follow this and additional works at: https://digitalcommons.usu.edu/sdl_pubs

\section{Recommended Citation}

Hansen, S.; Peterson, J.; Esplin, R.; and Tansock, J., "Component Level Prediction Versus System Level Measurement of SABER Relative Spectral Response" (2003). Space Dynamics Lab Publications. Paper 57. https://digitalcommons.usu.edu/sdl_pubs/57

This Article is brought to you for free and open access by the Space Dynamics Lab at DigitalCommons@USU. It has been accepted for inclusion in Space Dynamics Lab Publications by an authorized administrator of DigitalCommons@USU. For more information, please contact digitalcommons@usu.edu.

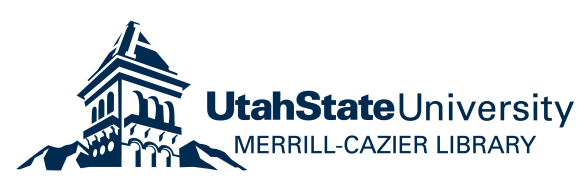


This article was downloaded by: [Utah State University Libraries]

On: 15 August 2014, At: 11:31

Publisher: Taylor \& Francis

Informa Ltd Registered in England and Wales Registered Number: 1072954 Registered office: Mortimer House, 37-41 Mortimer Street, London W1T 3J H, UK



\section{International J ournal of Remote Sensing}

Publication details, including instructions for authors and subscription information: http:// www. tandfonline.com/loi/tres20

\section{Component level prediction versus system level measurement of SABER relative spectral response}

S. Hansen ${ }^{a}$, J . Peterson ${ }^{a}$, R. Esplin ${ }^{a} \&$ J. Tansock ${ }^{a}$

${ }^{a}$ Space Dynamics Laboratory, Utah State University, 1747 North Research Park Way, Logan, UT, 84341, USA

Published online: 26 Nov 2010.

Hansen, S., J. Peterson, R. Esplin, and J. Tansock. 2003. "Component Level

Prediction versus System Level Measurement of SABER Relative Spectral

Response." International Journal of Remote Sensing 24 (2): 389-402.

doi:10.1080/01431160304968.

To cite this article: S. Hansen , J. Peterson, R. Esplin \& J. Tansock (2003) Component level prediction versus system level measurement of SABER relative spectral response, International J ournal of Remote Sensing, 24:2, 389-402, DOI: $10.1080 / 01431160304968$

To link to this article: http:// dx.doi.org/10.1080/01431160304968

\section{PLEASE SCROLL DOWN FOR ARTICLE}

Taylor \& Francis makes every effort to ensure the accuracy of all the information (the "Content") contained in the publications on our platform. However, Taylor \& Francis, our agents, and our licensors make no representations or warranties whatsoever as to the accuracy, completeness, or suitability for any purpose of the Content. Any opinions and views expressed in this publication are the opinions and views of the authors, and are not the views of or endorsed by Taylor \& Francis. The accuracy of the Content should not be relied upon and should be independently verified with primary sources of information. Taylor and Francis shall not be liable for any losses, actions, claims, proceedings, demands, costs, expenses, damages, and other liabilities whatsoever or howsoever caused arising directly or indirectly in connection with, in relation to or arising out of the use of the Content.

This article may be used for research, teaching, and private study purposes. Any substantial or systematic reproduction, redistribution, reselling, loan, sub-licensing, systematic supply, or distribution in any form to anyone is expressly forbidden. Terms $\&$ Conditions of access and use can be found at http:// www.tandfonline.com/page/terms-and-conditions 


\title{
Component level prediction versus system level measurement of SABER relative spectral response
}

\author{
S. HANSEN, J. PETERSON, R. ESPLIN and J. TANSOCK \\ Space Dynamics Laboratory/Utah State University, 1747 North Research Park
} Way, Logan, UT 84341, USA

\begin{abstract}
A 10-channel infrared (1.25-17.24 $\mu \mathrm{m}$ wavelength) radiometer known as SABER (Sounding of the Atmosphere using Broadband Emission Radiometry) is one of four experiments that will fly on the TIMED (Thermosphere, Ionosphere, Mesosphere, Energetics, and Dynamics) mission that was successfully launched on 7 December 2001. Theoretical models of the relative spectral response (RSR) for each SABER channel were developed during the design and build of the instrument. The RSR calculations were then refined using a component level technique where theoretical predictions of filter transmittance were replaced with measurements from filter witness samples. During SABER ground calibration, full system measurements of RSR were performed using a Michelson step-scan interferometer to present an interferometrically modulated infrared source to the instrument with the resultant interferogram recorded by the instrument detectors. Fourier transform of this interferogram and correction of the resulting spectrum for the spectral output of the interferometer and the transmittance of any intervening optics provide a measurement of the system level RSR. We compare the full system level measurements with the theoretical and component level RSR predictions for both in-band and out-of-band spectral regions. Our results show that the system level method for determining RSR provides the clearest picture of the instrument's spectral properties.
\end{abstract}

\section{Introduction}

The Sounding of the Atmosphere using Broadband Emission Radiometry (SABER) instrument is a 10-channel radiometer designed to perform atmospheric limb measurements between ground level and $200 \mathrm{~km}$ altitude, with $2 \mathrm{~km}$ spatial vertical resolution. The SABER instrument was launched in 2001 aboard the Thermosphere, Ionosphere, Mesosphere, Energetics and Dynamics (TIMED) mission spacecraft.

The SABER channels were designed to cover a spectral range of $1.25-17.24 \mu \mathrm{m}$. The requisite 5\% cut-on and cut-off points and the detector material for each channel are shown in table 1. Filters were designed from these requirements to give a desired band-pass when combined with the SABER instrument mirror reflectance and

Paper presented at the Conference on Characterization and Radiometric Calibration for Remote Sensing held at Utah State University, Logan, 9-11 November 1999.

International Journal of Remote Sensing

ISSN 0143-1161 print/ISSN 1366-5901 online (C) 2003 Taylor \& Francis Ltd

http://www.tandf.co.uk/journals

DOI: $10.1080 / 01431160210154083$ 
Table 1. SABER channel specifications.

\begin{tabular}{lccc}
\hline SABER Channel \# & 5\% Cut-on $(\mu \mathrm{m})$ & 5\% Cut-off $(\mu \mathrm{m})$ & Detector \\
\hline 1 & 14.71 & 15.75 & HgCdTe \\
2 & 13.16 & 17.24 & HgCdTe \\
3 & 13.16 & 17.24 & HgCdTe \\
4 & 8.77 & 9.90 & HgCdTe \\
5 & 6.41 & 7.25 & HgCdTe \\
6 & 5.19 & 5.63 & InSb \\
7 & 4.17 & 4.41 & InSb \\
8 & 1.92 & 2.22 & InSb \\
9 & 1.55 & 1.74 & InSb \\
10 & 1.25 & 1.29 & InGaAs \\
\hline
\end{tabular}

response curve for the appropriate detector. These predictions are presented in the following section. Spectral curves for the three relative spectral response (RSR) determination methods will be shown for channels 1,4 , and 9 , as examples of typical results, although summary results for all SABER channels will be given in table 2 .

\section{Theoretical prediction of RSR}

The SABER filters were designed and manufactured by Optical Coating Laboratory Incorporated. The filter design provided band-pass curves, which predict both in-band and out-of-band behaviour. EG\&G Optoelectronics, the detector manufacturer, provided spectral response data for the different detector technologies, and the National Institute of Standards and Technology measured the reflectance of witness samples for the gold mirrors used in the SABER instrument.

The theoretical predicted level RSR was calculated by factoring together the filter band-pass curves, corresponding detector curves, and the mirror reflectance; the resulting product was then normalized to the in-band peak. This calculation is shown in the following equation:

$$
R S R=\frac{1}{R S R_{\text {peak }}} T_{\text {filter }} R_{\text {detector }} r_{\text {mirror }}
$$

where $T_{\text {filter }}, R_{\text {detector }}$, and $r_{\text {mirror }}$ are the filter transmittance, detector response, and mirror reflectance. The composite in-band and out-of-band results, and separate in-band regions for channels 1, 4, and 9, are given in figures 1-6. Figures 1, 3, and 5 show the composite in-band and out-of-band data plotted on a log scale to make the out-of-band regions visible, and figures 2, 4, and 6 show linear plots of the in-band regions.

\section{Component level measurement of RSR}

Following fabrication of the actual filters, the transmittance of filter witness samples was measured. These transmittance measurements replaced the design predictions of filter transmittance in the RSR calculation (equation (1)) to generate component level measurements of RSR. Detector response measurements were not available, so theoretical curves were used for this calculation.

The transmittance measurements used in these component level calculations do not show out-of-band transmittance less than three to four orders of magnitude 
Table 2. SABER channel equivalent ideal bandwidths.

\begin{tabular}{|c|c|c|c|c|c|c|}
\hline \multirow[b]{2}{*}{ SABER channel number } & \multicolumn{2}{|c|}{ System level } & \multicolumn{2}{|c|}{ Component level } & \multicolumn{2}{|c|}{ Prediction } \\
\hline & Bandwith $(\Delta \lambda, \mu \mathrm{m})$ & Uncertainty $(\%)$ & Bandwith $(\Delta \lambda, \mu \mathrm{m})$ & Error $(\%)$ & Bandwith $(\Delta \lambda, \mu \mathrm{m})$ & Error $(\%)$ \\
\hline 1 & 0.79 & 1.81 & 0.804 & 1.22 & 0.820 & 3.23 \\
\hline 2 & 2.88 & 2.31 & 3.56 & 23.5 & 3.49 & 21.0 \\
\hline 3 & 3.47 & 1.95 & 3.56 & 2.46 & 3.49 & 0.403 \\
\hline 4 & 0.954 & 3.38 & 0.954 & 0.0536 & 0.933 & -2.15 \\
\hline 5 & 0.745 & 1.29 & 0.769 & 3.25 & 0.749 & 0.618 \\
\hline 6 & 0.130 & 3.74 & 0.126 & -3.15 & NA & NA \\
\hline 7 & 0.126 & 2.14 & 0.122 & -3.26 & 0.139 & 10.5 \\
\hline 8 & 0.233 & 1.22 & 0.230 & -1.33 & 0.242 & 4.10 \\
\hline 9 & 0.144 & 1.21 & 0.143 & -0.562 & 0.155 & 7.38 \\
\hline 10 & 0.0273 & 1.28 & 0.0260 & -4.54 & 0.0270 & -1.16 \\
\hline
\end{tabular}




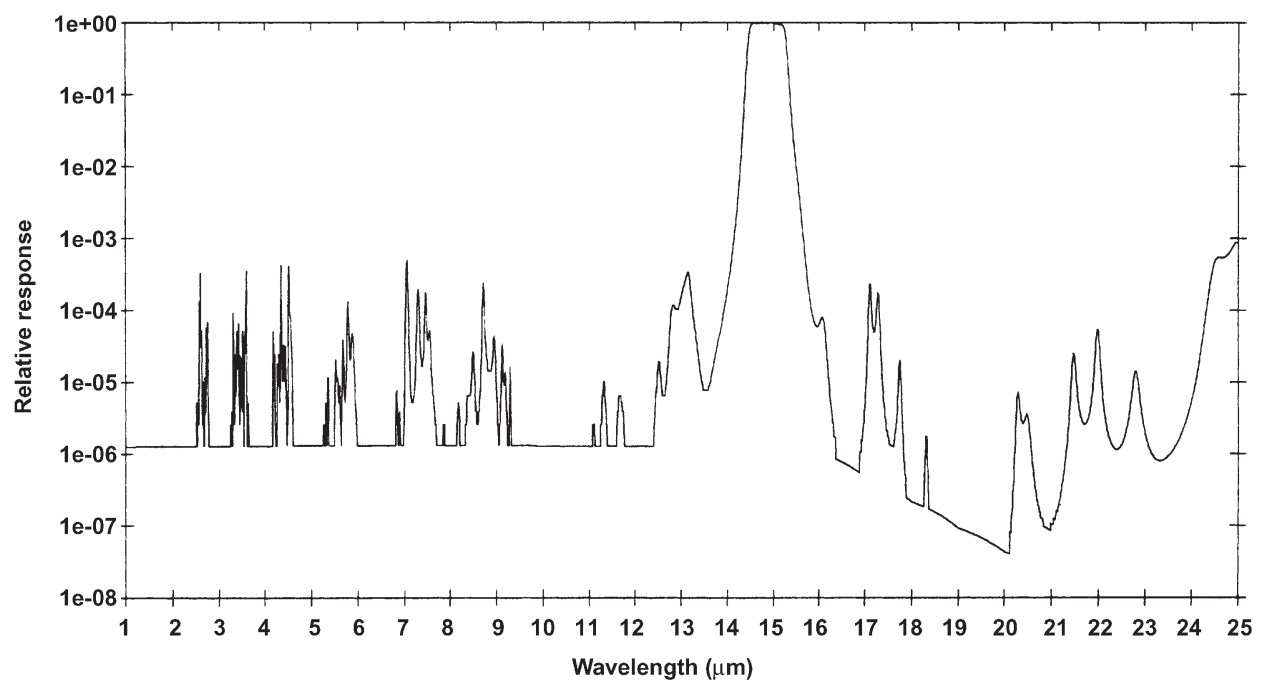

Figure 1. Channel 1 system responsivity from design predictions.

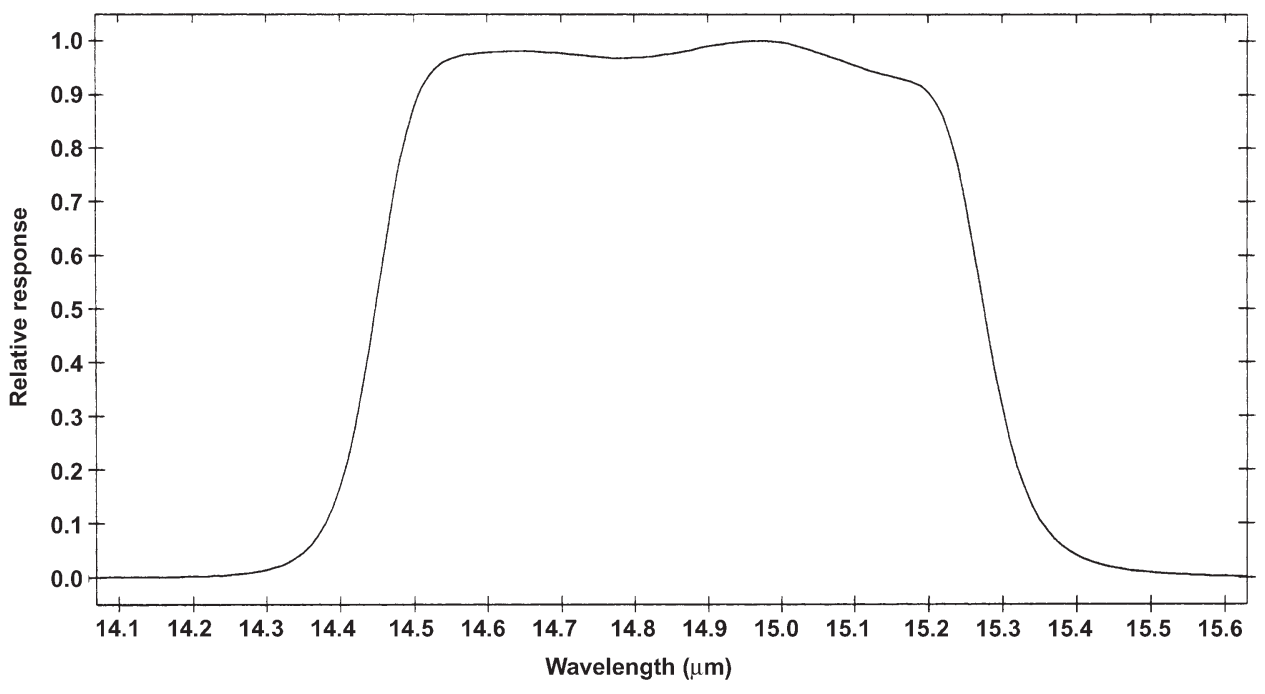

Figure 2. Channel 1 system pass-band from design predictions.

below the in-band peak, thus, only the in-band results are included. These results for channels 1,4 , and 9 are shown in figures 7-9.

\section{Full system measurement of RSR}

Ground measurements of RSR were performed on the SABER instrument in April and July 1999. These measurements were obtained using a step-scan Michelson interferometer (BioRad FTS 60A) to present an interferometrically modulated infrared source to the instrument with the resultant interferograms recorded by the instrument detectors (Hansen et al. 1998). Fourier transform of the interferograms 


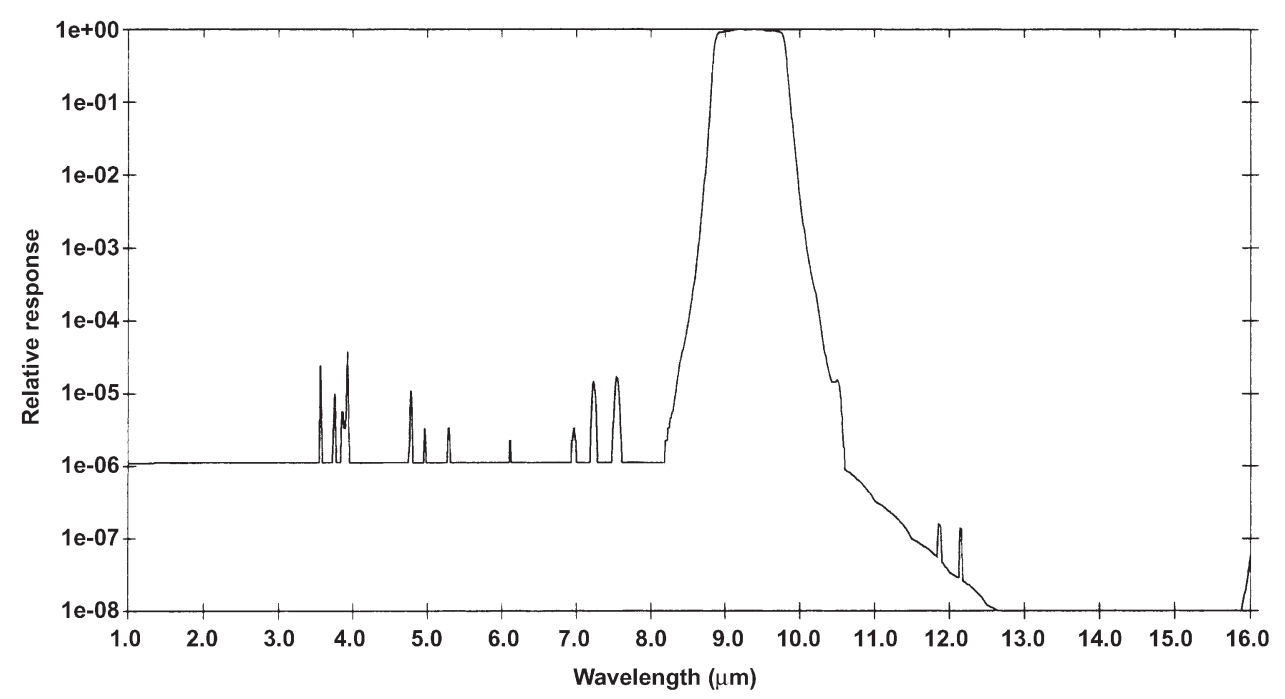

Figure 3. Channel 4 system responsivity from design predictions.

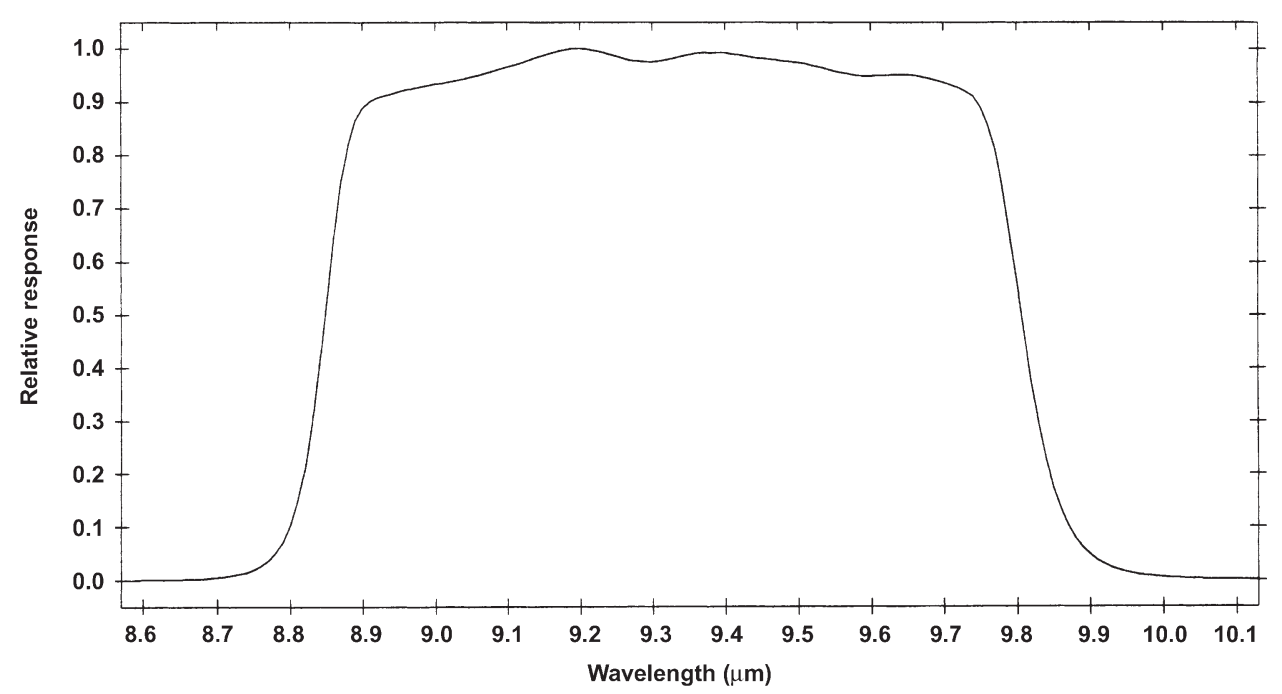

Figure 4. Channel 4 system pass-band from design predictions.

and correction of the resulting spectra for the spectral output of the interferometer and the transmittance of any intervening optics provided a measurement of system level RSR. A large area pyroelectric detector (Servo Corporation of America, customized model 1550) coated with Z306 flat black paint was used as a spectral reference standard. Surface Optics Corporation measured the absorptance of detector element witness samples to determine the reference detector relative spectral responsivity.

The composite in-band and out-of-band system level RSR curves obtained using this measurement technique are shown for channels 1, 4 and 9 in figures 10, 12, and 14. Separate measurements were made for in-band and out-of-band regions and were 


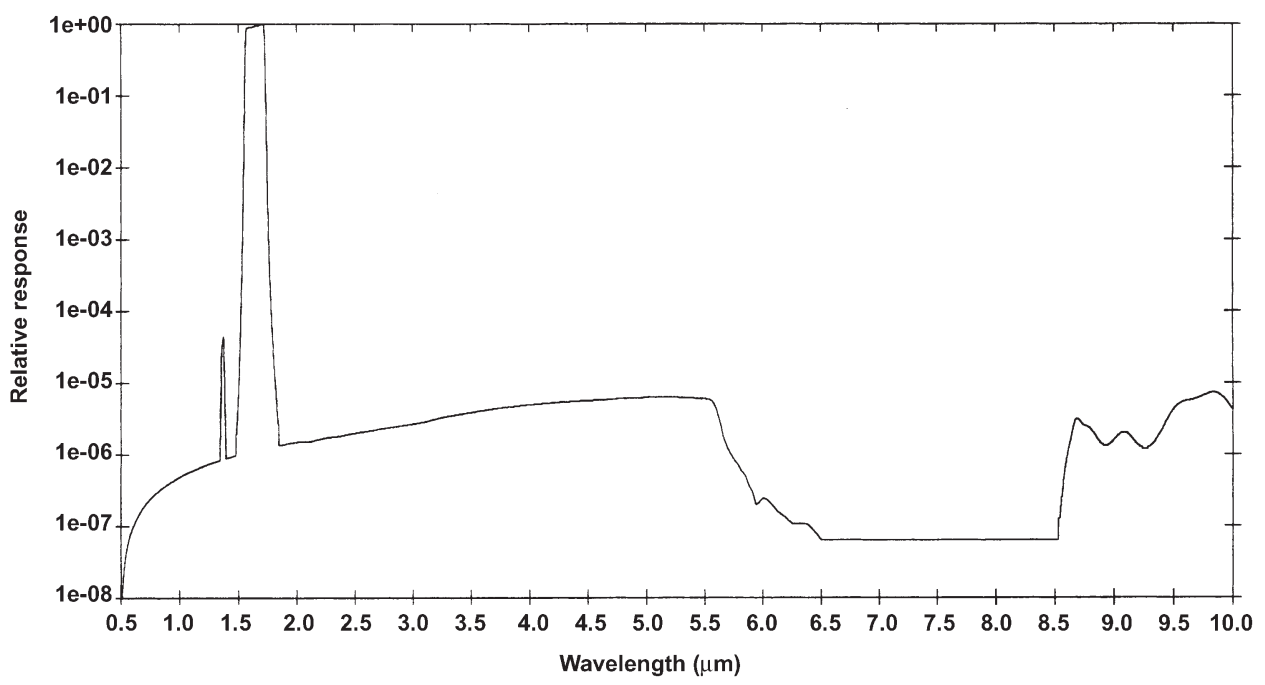

Figure 5. Channel 9 system responsivity from design predictions.

combined to form a single curve. Out-of-band measurements were made using a cascaded filter technique (Kemp et al. 1989) that limits in-band energy and permits out-of-band measurements at much lower levels than could otherwise be achieved. The cascaded filter technique uses a separate filter with a pass-band different from that of the filter or channel under test to block the test pass-band, while a low level out-of-band measurement is made in the pass-band of the blocking filter. In-band system level RSR was measured using the interferometer technique, and in-band close-ups for channels 1, 4 and 9, are shown in figures 11, 13, and 15, respectively.

\section{Comparison}

Plotting the in-band RSR curves of the three different measurement approaches on the same scale illustrates the quantitative differences of the responsivity measurements. Because RSR is a relative value, i.e. each curve is normalized to the maximum in-band value, only differences in the shapes of the RSR curves are critical. Overlay plots of the in-band curves from the three different methods are shown for channels 1,4 , and 9 in figures $16-18$. The system level measurement is shown as a solid line, while the predicted and component level data are shown as dotted and dashed lines, respectively.

Integration of the in-band RSR for each method, as shown in equation (2),

$$
\int_{\text {passband }} \operatorname{RSR}(d \lambda)=\Delta \lambda_{\text {ideal }}
$$

provides an equivalent bandwidth, $\Delta \lambda_{\text {ideal }}$, that is the RSR of an idealized sensor having an in-band response of one and a response of zero in all out-of-band regions. This equivalent ideal bandwidth allows comparison of the RSR measurements for each of the three different methods described in this paper. The resulting bandwidths for each method, expressed in units of $\Delta$ wavelength, are shown in table 2 . The component and prediction level in-band values are compared with the full system 


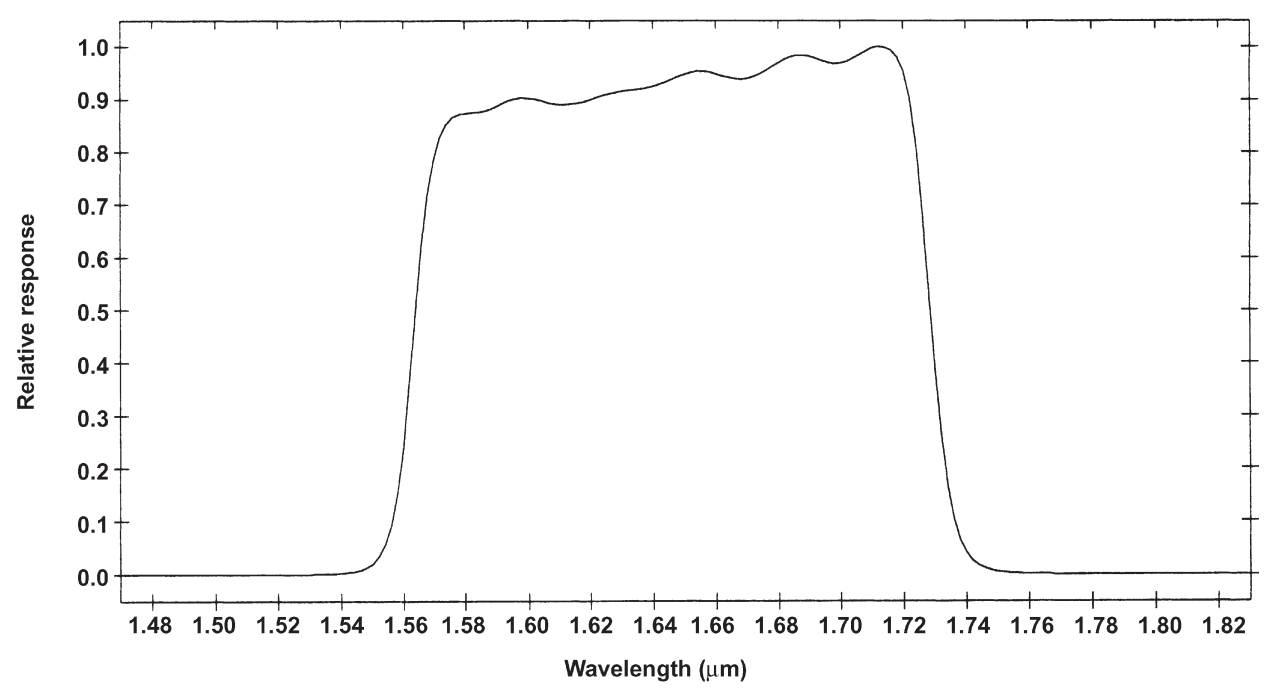

Figure 6. Channel 9 system pass-band from design predictions.

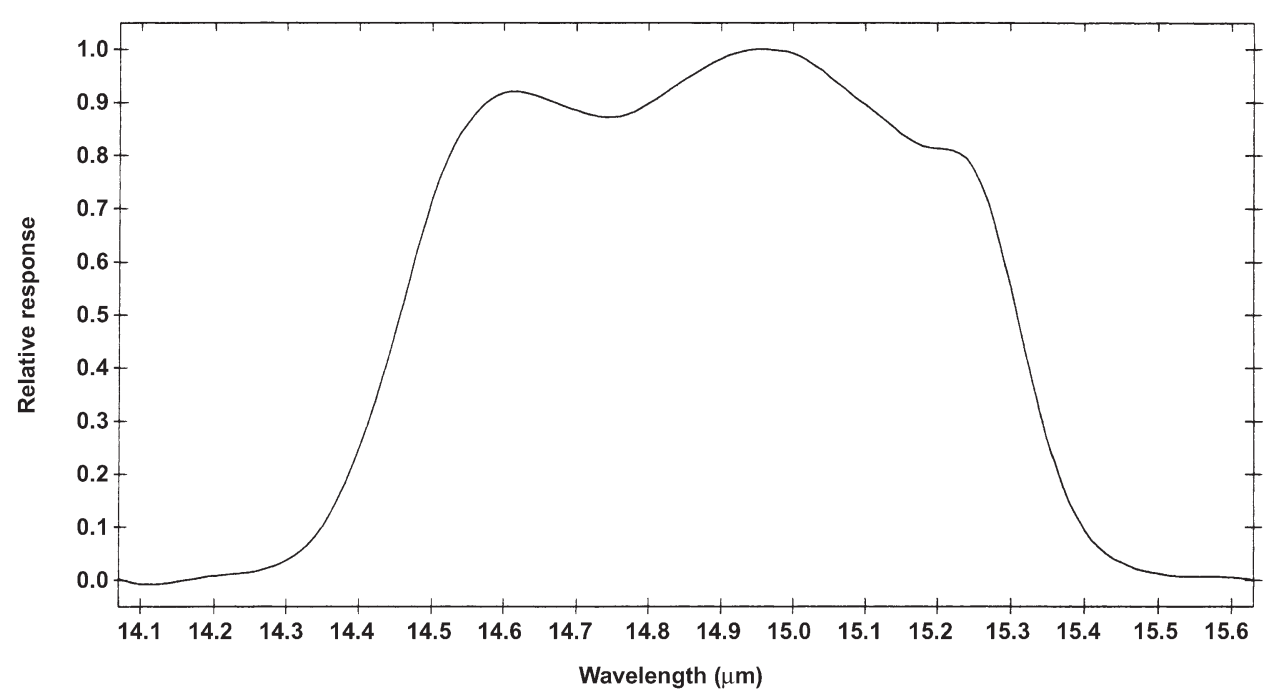

Figure 7. Channel 1 system pass-band from component measurements.

level transmittance values and the relative differences are shown as the percentage error.

The results shown in table 2 show close agreement between the system level and component level measurements while the predicted level values are less similar; this would be expected as the component and system level measurements represent actual hardware data. The difference between system level and component level measurements ranges from 0.5 to $4.5 \%$ for all channels except channel 2, compared with a typical system level measurement uncertainty between 1.2 and $3.7 \%$. The component level result for channel 2 shows an error of $23.5 \%$ although the explanation for this result has not yet been identified. The average error for the predicted level RSR values is approximately $5 \%$. It should be re-emphasized that the differences 


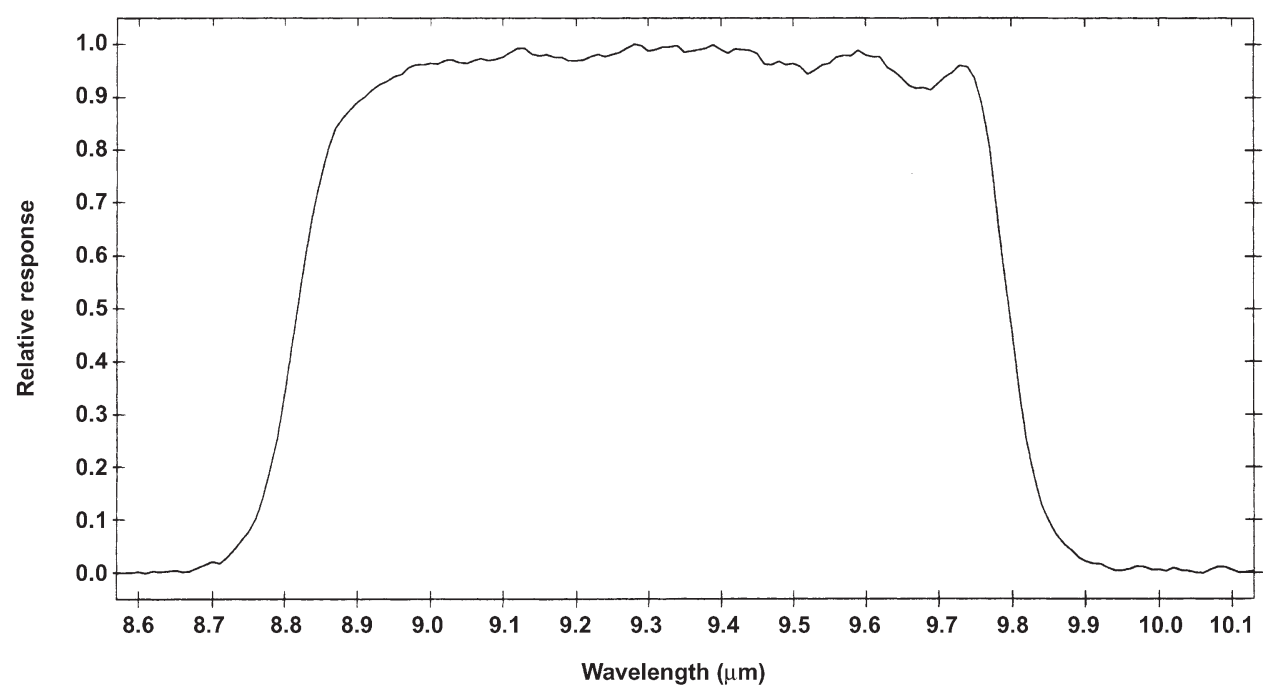

Figure 8. Channel 4 system pass-band from component measurements.



Figure 9. Channel 9 system pass-band from component measurements.

reported are a result of differences in curve shape, not amplitude, as the RSR curves were all peak normalized to one before integration.

In addition to the in-band information gained from the full system level measurement, the out-of-band measurements are also revealing. The comparison of the full system out-of-band measurement of channel 1 with the predicted level RSR for the same channel is shown in figure 19. The system level measurement is plotted as a dashed line, while the predicted data are shown as a solid line. It is worthwhile to note the agreement between the predicted and full system measurement techniques for the regions between 1 and $10 \mu \mathrm{m}$ of the out-of-band peaks.

Comparison of the system level out-of-band measurement with the predicted level RSR for channel 4 is shown in figure 20. Again there is correspondence between 


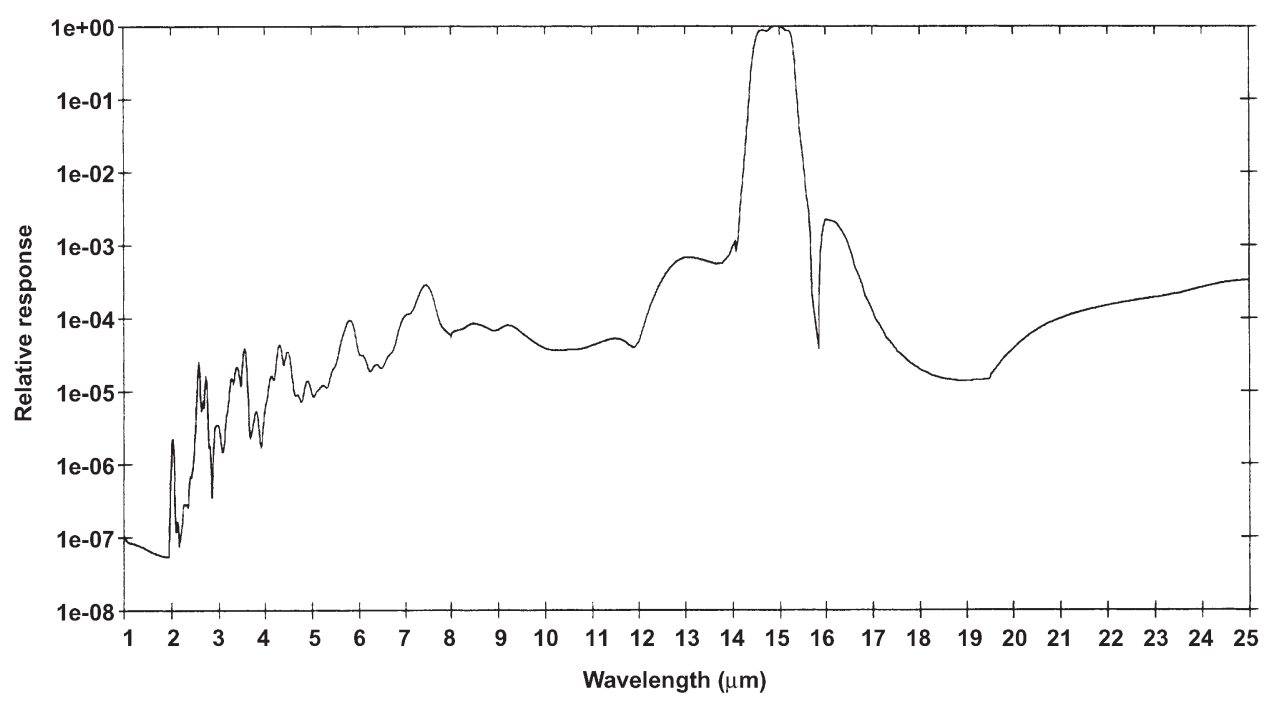

Figure 10. Channel 1 system responsivity from system calibration.

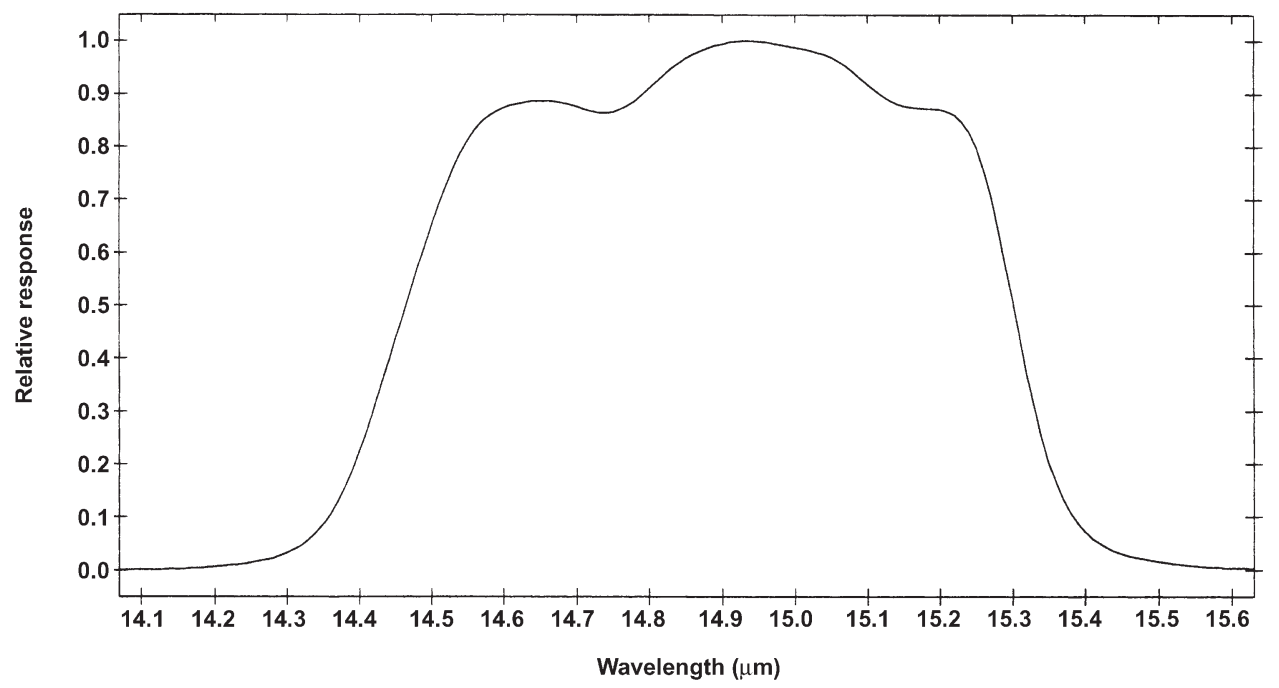

Figure 11. Channel 1 system pass-band from system calibration.

the model prediction and system RSR measurement, notably in the 3.5 and $4.0 \mu \mathrm{m}$ range. In addition, the full system measurement identified additional out-of-band structure not predicted by the theoretical model, although this is below the out-of-band blocking requirement for the filter.

The predicted RSR for channel 9 shows only limited out-of-band structure therefore no comparison was made. However, as indicated in figure 14, the full system RSR measurement identified peaks in the out-of-band response for channel 9 around $4 \mu \mathrm{m}$, although this structure is still below the out-of-band blocking requirement for that filter. 


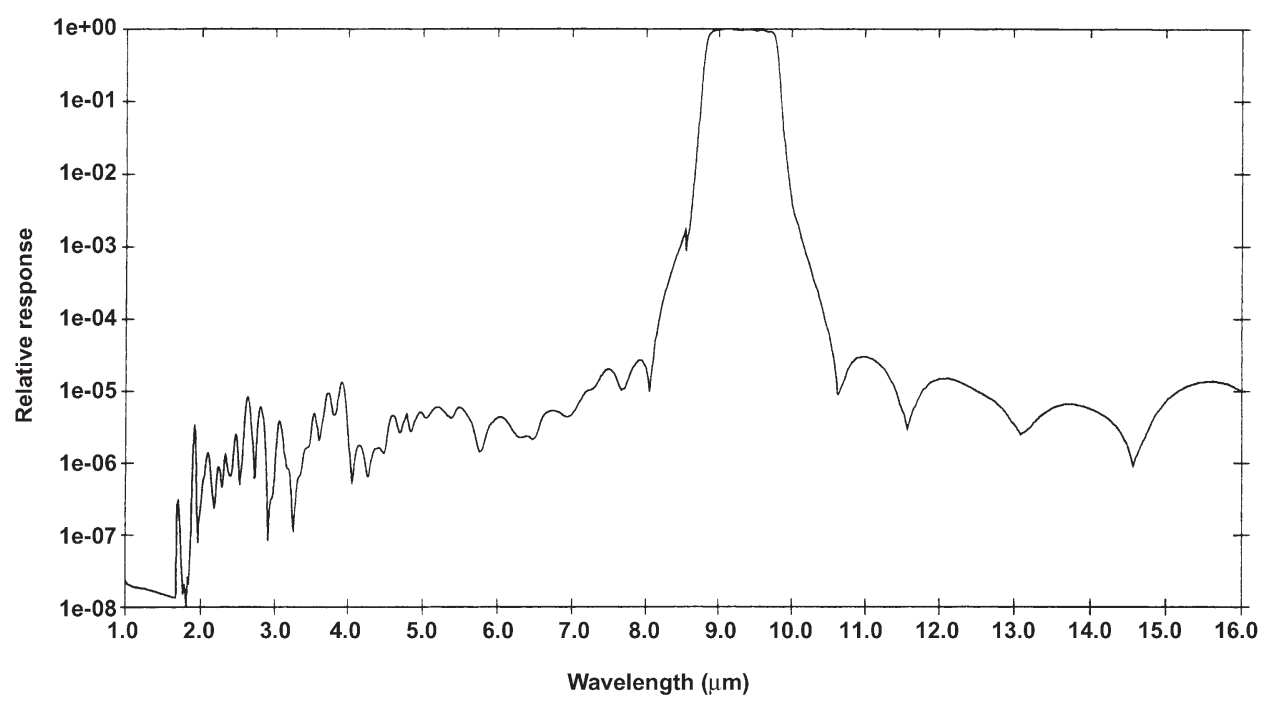

Figure 12. Channel 4 system responsivity from system calibration.

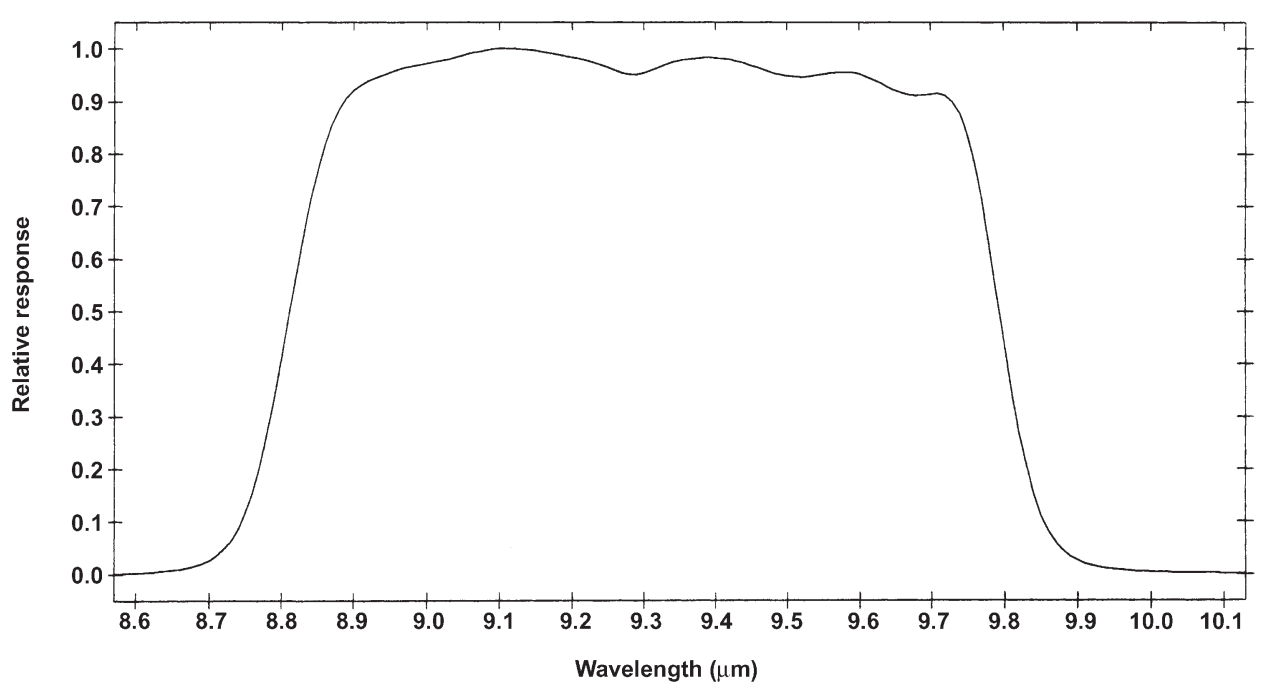

Figure 13. Channel 4 system pass-band from system calibration.

\section{Conclusion}

Space Dynamics Laboratory routinely performs full system RSR measurements as part of the ground calibration procedure. System level determinations address factors that may not be accounted for in theoretical predictions or component level measurements performed on filter witness samples; these factors might include differences in temperatures, and the optical f-numbers or incident angles. For example, filter witness sample measurements are often made at temperatures and optical configurations different from those of the actual instrument. Although models can be applied to attempt to correct for these differences, the results, once again, are subject to prediction risk. These risks can be eliminated by performing a full-up system test under the conditions which will be encountered in operation. 


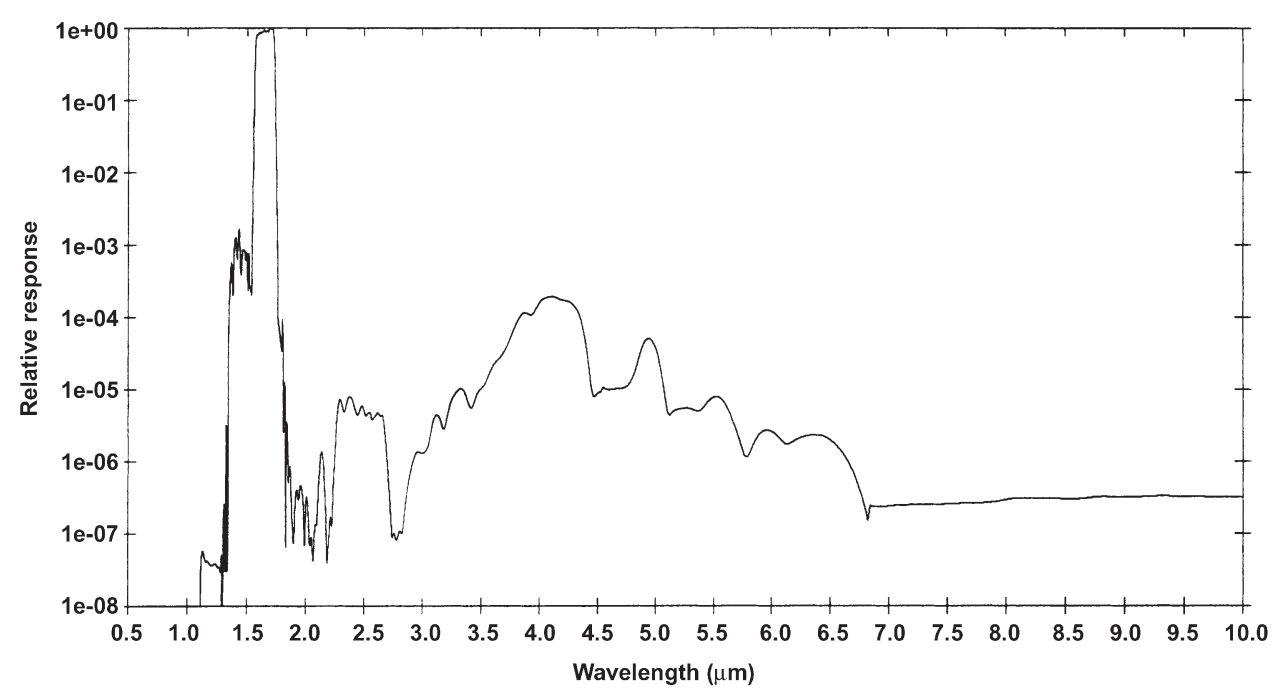

Figure 14. Channel 9 system responsivity from system calibration.

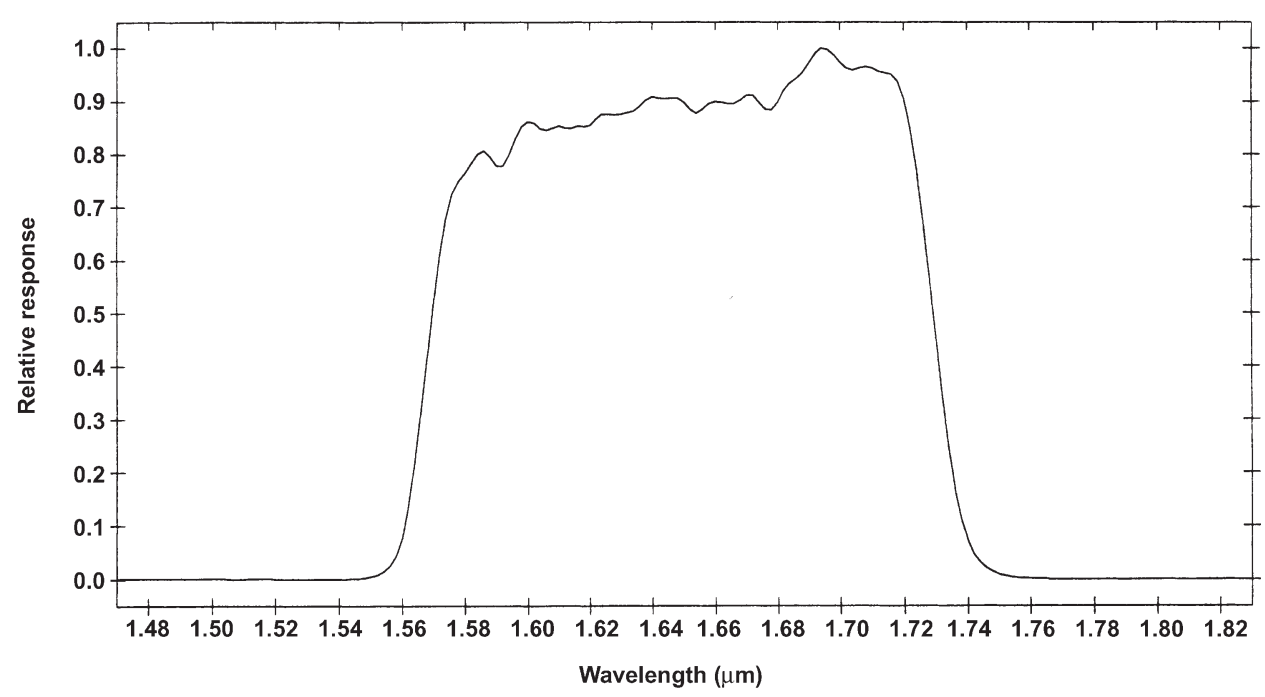

Figure 15. Channel 9 system pass-band from system calibration.

End-to-end system measurements may also flag otherwise undetected fabrication problems, i.e. contamination of or damage to the instrument, that can impact sensor response. Thus, a full system test of RSR can provide a valuable verification of instrument function and quality, thereby reducing the potential of calibration error.

The benefits of employing the integrated system level RSR are clearly seen in our comparisons where the system level measurement of SABER channel 2 differ by over $20 \%$ from the component level measurement. Had a full system level RSR test not been performed, and the component level measurement used instead, the resulting radiometric measurements would unknowingly include this error.

Furthermore, a full system level measurement of RSR is an important tool in the identification of out-of-band leaks. Because of interactions between the different 


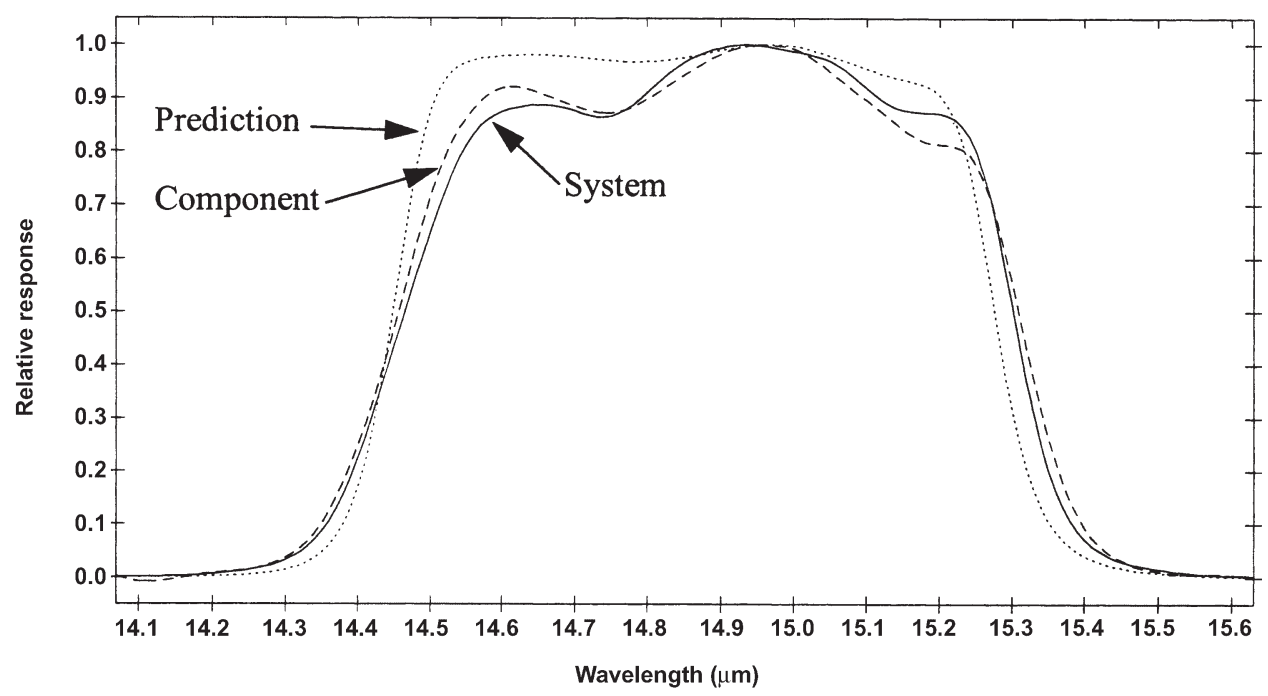

Figure 16. Channel 1 in-band responsivity comparison.

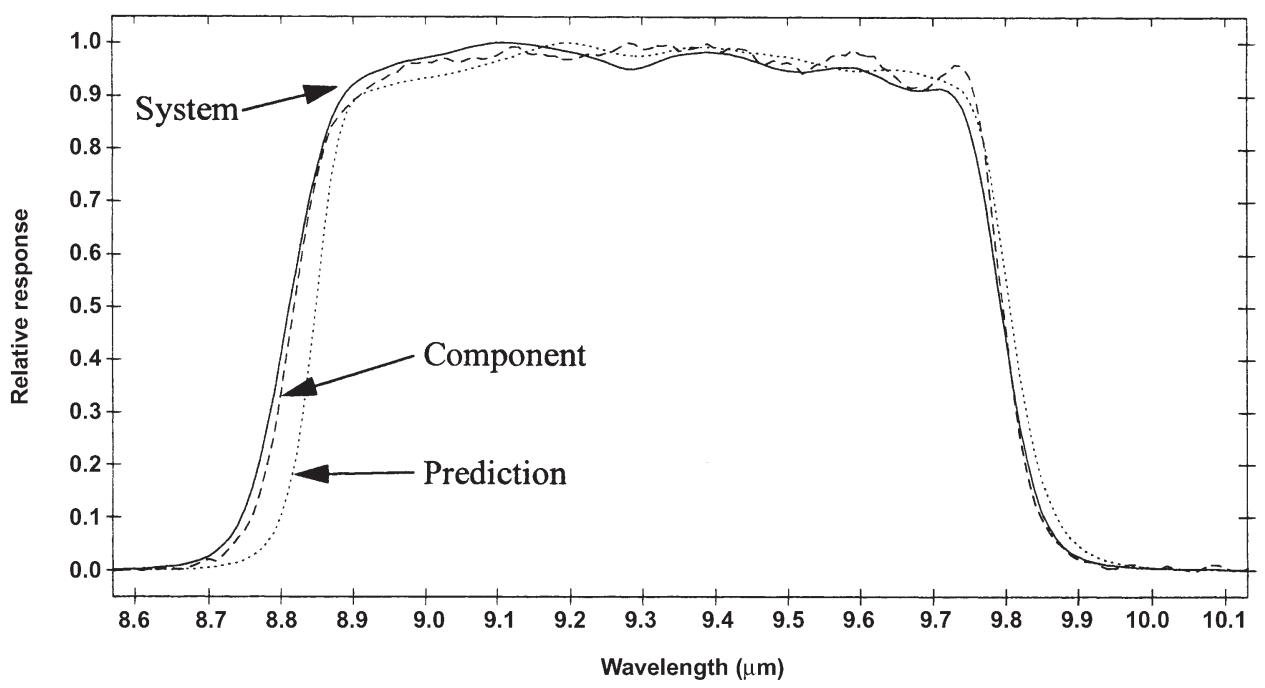

Figure 17. Channel 4 in-band responsivity comparison.

components of a sensor system, the out-of-band response is often more difficult to predict than the in-band relative response, making a final system level test most important when out-of-band performance is critical. Moreover, it is possible to probe the out-of-band performance of a sensor to better than three orders of magnitude below the in-band peak, using the cascaded filter technique mentioned in this paper.

In conclusion, full system level RSR measurements are a critical part of ground calibration testing. This measurement approach gives the clearest picture of the system as a whole, providing an end-to-end characterization of instrument spectral performance, as well as addressing instrument quality in general. Furthermore, error risk associated with overlooked or unpredicted factors is reduced or eliminated, 


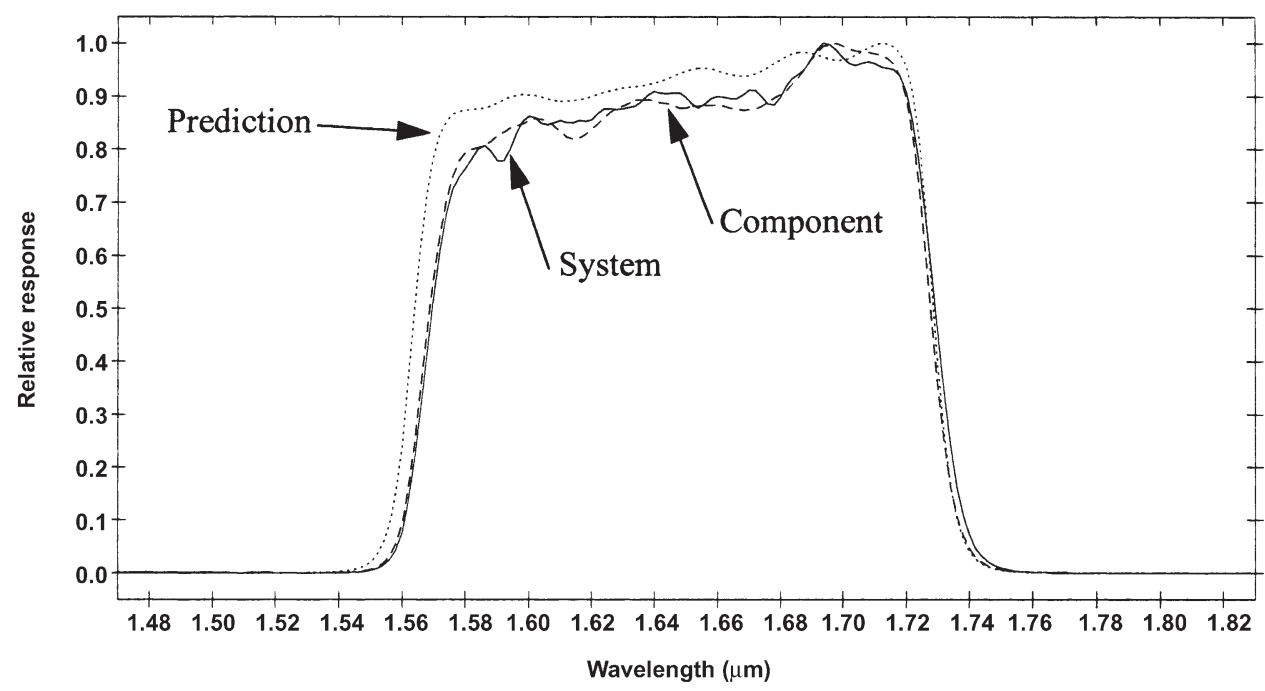

Figure 18. Channel 9 in-band responsivity comparison.

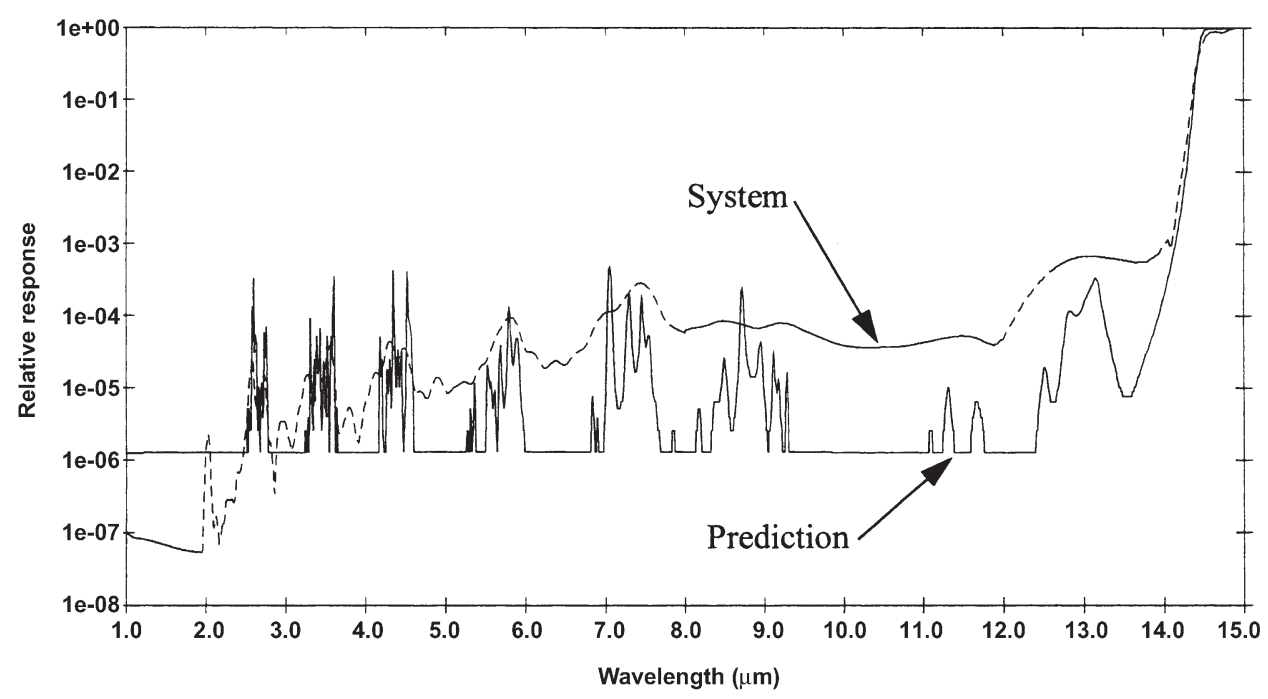

Figure 19. Channel 1 out-of-band responsivity comparison.

making the system level RSR determination method a valuable tool in the calibration of spectral instrumentation.

\section{Acknowledgments}

The authors wish to thank Jim Miller and Bill Roettker of NASA Langley Research Center as well as Jim Russell of Hampton University for their support and encouragement, without which this work would not have been possible. The SABER instrument was funded by NASA under contracts NAS1-20080 and NAS1-20476 and manufactured by Space Dynamics Laboratory/Utah State University. 


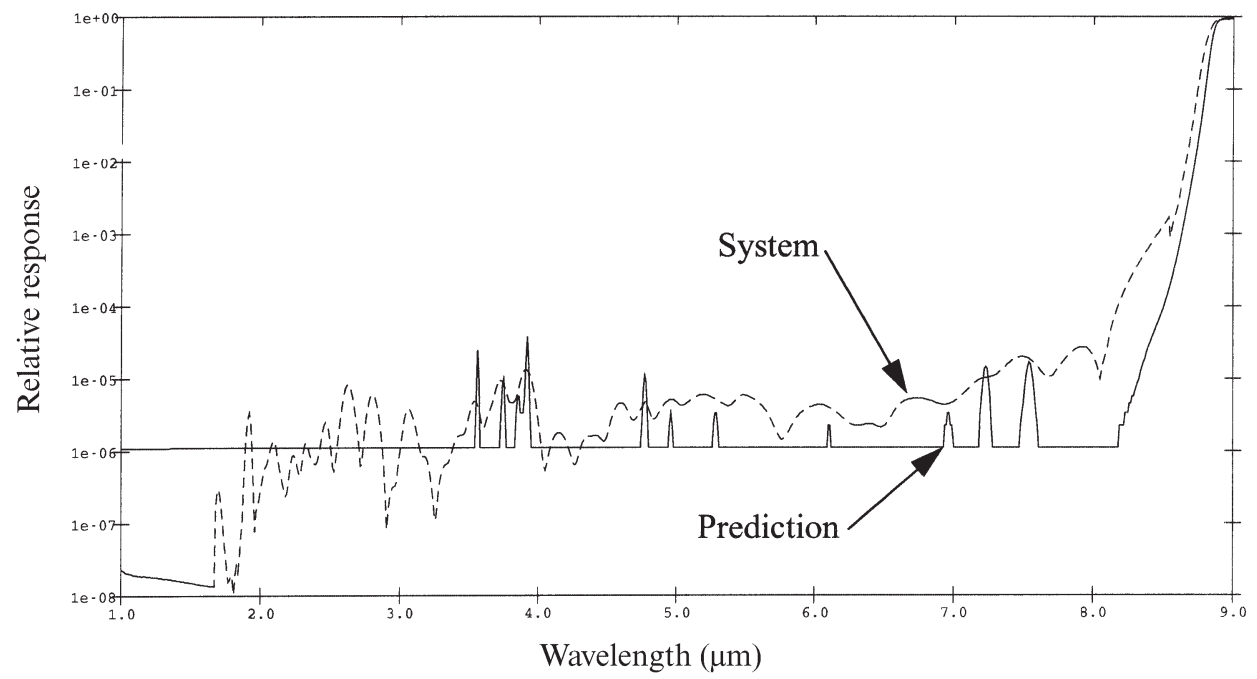

Figure 20. Channel 4 out-of-band responsivity comparison.

\section{References}

Hansen, S., Peterson, J., and TANsock, J., 1998, Relative spectral response reference detector update. Proceedings of the Eighth Infrared Radiometric Sensor Calibration Symposium (Utah: Utah State University).

Kemp, J., Huppi, E. R., and Madigan, M., 1989, Measurements of high out-of-band filter rejection characteristics. Proceedings of SPIE, 1112, 433-441. 